\title{
Original Article \\ Modeling the Red-shanked Douc
(Pygathrix nemaeus) distribution in Vietnam using Maxent
}

\author{
Nguyen Tuan Anh ${ }^{1}$, Le Duc Minh ${ }^{1,2, *}$, Pham Viet Hung ${ }^{2}$, Vu Thi Duyen ${ }^{1}$ \\ ${ }^{1}$ Faculty of Environmental Sciences, VNU University of Science, 334 Nguyen Trai, Hanoi, Vietnam \\ ${ }^{2}$ VNU Central Institute for Natural Resources and Environmental Studies, \\ 19 Le Thanh Tong, Hanoi, Vietnam
}

Received 9 May 2019

Revised 12 July 2019; Accepted 9 August 2019

\begin{abstract}
The Red-shanked Douc (Pygathrix nemaeus) is the only douc species recorded in all three countries of Indochina. It is classified as Endangered by IUCN, and is believed to have experienced a major drop of more than $50 \%$ of its population over the last 40 years. The known distribution of main P. nemaeus populations in Vietnam ranges from Pu Mat National Park, Nghe An Province in the North to the Kon Ha Nung, Gia Lai Province in the South. In this study, we used Maxent, a species distribution modeling approach that is shown to a have high predictive power even with low number of occurrence records, to predict the current distribution of the Red-shanked Douc in Vietnam based on published records. The results show that $P$. nemaeus inhabits a region from Nghe An to Kon Tum Province, with areas from Ha Tinh, Quang Binh, Quang Tri, Thua Thien - Hue, Da Nang - Quang Nam Provinces exhibiting the highest potential. With all model parameters already listed here, studies in the future may incorporate more occurrence records to develop better models, or other environmental variables to assess the influence of different factors on the species distribution. The results also suggest that species distribution modeling, coupled with a carefully checked and filtered occurrence dataset, as well as species-specific model fine-tuning and evaluating, can help address many conservation issues in Vietnam.
\end{abstract}

Keywords: Maxent, Red-shanked Douc, Species Distribution Modeling.

\footnotetext{
${ }^{*}$ Corresponding author.

E-mail address: le.duc.minh@hus.edu.vn

https://doi.org/10.25073/2588-1094/vnuees.4390
} 


\section{Introduction}

Doucs (genus Pygathrix) are members of the Old World monkey subfamily Colobinae [1]. This genus contains three species: The Redshanked Douc ( $P$. nemaeus), Grey-shanked Douc $(P$. cinerea), and Black-shanked Douc $(P$. nigripes). The doucs are found only in Indochina and all have limited geographic ranges, and have been threatened with the shrinking of forested habitat areas in their natural distributions [2].

The Red-shanked Douc is only douc species recorded in all three countries of Indochina. The core populations of the Red-shanked Douc now reside in Vietnam and Laos, and it was recently confirmed for northern Cambodia through a genetic analysis [3]. The extent of the species distribution in Cambodia is, however, still in question, and it is likely to be considerably restricted. The douc individuals from Cambodia share many characteristics with those from southernmost Laos [3-5]. The distribution of Pygathrix nemaeus in Vietnam ranges from $\mathrm{Pu}$ Mat National Park, Nghe An Province in the North $\left(19^{\circ} 02^{\prime} \mathrm{N}\right)$ to the Kon Ha Nung area, Gia Lai Province in the South $\left(14^{\circ} 33^{\prime} \mathrm{N}\right)$ [6].

The Red-shanked Douc occurs mainly in evergreen and semi-evergreen forests, and is sometimes associated with limestone forest, but this association is still in question. It is diurnal and arboreal, and was recorded at an elevation up to $1,600 \mathrm{~m}$. The doucs are highly folivorous, with around $75 \%$ of their diet consisting of leaves, and sometimes buds, fruit, seeds, and flowers [5-7]. Behavioral characteristics of this species make it an easy target for hunting, and recent field observations have suggested that the group size may vary considerably as a possible consequence of environmental and human disturbances [8-10].

It is classified as Endangered by IUCN [7], and is believed to have experienced a major decline of more than $50 \%$ of its population over the last 40 years due to a combination of war effects, habitat loss, and illegal hunting [7, 11]. The Red-shanked Douc is listed as "Endangered" in the Red Data Book of Vietnam (Ministry of Science, Technology, and Environment 2007). This species is also listed in
Appendix I of the Convention on International Trade in Endangered Species of Wild Fauna and Flora (CITES). Hunting is currently the main threat to the Red-shanked Douc, mostly for subsistence use and traditional medicine $[4,6,12]$. Destruction of its natural habitat is the second major threat to this species, as many areas in central Vietnam have been cleared and shifted to anthropogenic land uses due to the rapid growth of Vietnam population since the post war period [6]. As often the case with endangered species, laws and regulations created to protect them are difficult to enforce - even though the country has granted the Red-shanked Douc the highest protection status.

Background on Species Distribution Modeling (SDM)

SDM is a relatively new approach that is useful in studying biogeography and evolutionary ecology. It can be used to assess the suitability of distribution range for a taxon, and is become a common approach employed to address conservation issues [13-16]. In general, SDMs use the relationship between observed points of occurrence and influencing variables (termed "environmental variables) to generate a probability map rating the suitability for a species of a given area. SDMs can help to locate areas climatically suitable for a species but have not yet been discovered [13, 17]; to identify cryptic species lineages whose other traits such as morphological characteristics, phylogenic sorting, and reproductive isolation may be incomplete and need more convincing evidences [14]; to design protected areas that accounts for future changes in climate and the distribution of inhabited taxa [18-21]; to determine what environmental variables may contribute most in determining the species' distribution [22, 23]; and to examine the niche conservatism of ecological traits over evolutionary changes $[24,25]$. SDMs also play a vital role to answer crucial questions on geographic distributions of species [26]. For instance, in conservation biology and wildlife management, SDMs provide significant information for making informed decisions [27]. This wide range of applications had led to the development of many different SDMs approaches. The accuracy of the 
predicted results depends on a number of factors, such as the complexity and correlation of the models, the environmental variables and occurrence data inputs [14].

In this paper, we reviewed literature to gather known records of the Red-shanked Douc in Vietnam. We then incorporated distribution data into SDM to generate a distribution map of the species using a maximum entropy approach (Maxent), to help advance understanding and conservation measures for this endangered and keystone species.

\section{Methods}

\section{Literature reviews}

We reviewed the available records of Pygathrix nemaeus by searching the Core Collection of the Web of Science, Google Scholar, and ResearchGate using the following queries: "Pygathrix nemaeus", "Pygathrix", "nemaeus", "Red-shanked Douc", "Douc", "Chà vá", "Chà vá chân nâu", "Chà vá chân đỏ", and "Vooc ngũ sắc". In addition, library archives, reports, and specimens from related institutions were also examined. The collected records were then evaluated, checked, and filtered to avoid erroneous locations, and then the final set was used to train SDM for the Red-shanked Douc. Records that have no coordinate information (e.g., from checklists, news, interviews) were only used to evaluate the model.

\section{Data pre-processing}

From the collected records, to avoid spatial autocorrelation, we used the spThin package [28] in R [29] to thin out localities with $10 \mathrm{~km}$ distance [14], which resulted in the final set of 51 localities from the original 62 records (Table 1, Fig. 1). We constructed the SDM using 19 bioclimatic variables at 30 arcsec resolution available at WorldClim database [30], and restrict them to study site by using Minimum Convex tool at 0.7 degree buffer in ArcGIS. To reduce model complexity, we ran a jackknife analysis to measure the importance of variables, and we also calculated Pearson's correlation coefficient to identify highly correlated variable pairs $(r \geq|0.75|)$ using ENMTools [31]. We used both results, as well as ecological reasoning to reduce 19 starting variables to 5 variables. The final set of variables included iso-thermality, temperature annual range, mean temperature of driest quarter, precipitation of driest month, and precipitation of seasonality.

\section{Model Run and Evaluation}

We used Maxent software v. 3.4.1 [32, 33] to run the SDM. Unlike many others, Maxent does not require absence records [32], and performs reasonably well even when only a few occurrence records are available [13, 14]. Regularization multiplier was selected by testing a range of values from 0.5 to 10 , with a 0.5 increment, and models with the highest area under the curve (AUC) of the receiver-operating characteristic plot were selected. AUC values ranged from 0.5 for models with predictive power no better than random to 1.0 for models giving perfect predictions [34]. This resulted in regularization multiplier equal to 1.5 for subsequent models. Other model parameters (e.g., convergence threshold, and feature selection) followed recommendations from model developers [32].

We used a fivefold cross-validation method to build the model [35]. This method randomly separates occurrence data into five equally sized partitioned folds. Five models are then created, leaving out one fold each time as test data to help evaluate the model. To assess model performance and select the most suitable one, ENMTools was used to calculate the AIC (Akaike information criterion) [31], under the assumption that the better the model, the lower the AIC value. For the final model, we used equal training sensitivity and specificity threshold to classify between suitable and unsuitable areas [36]. We then overlaid the suitability layer over the Vietnam protected area layer to determine conservation priority areas for the Red-shanked Douc.

\section{Results and discussion}

We obtained 62 known records of the Redshanked Douc based on other peer-reviewed papers, books, and reports (Table 1, Fig. 1). 
Table 1. Known distribution records in Vietnam for the Red-shanked Douc

\begin{tabular}{|c|c|c|c|c|c|}
\hline No. & Longitude & Latitude & $\begin{array}{c}\text { Record } \\
\text { year/duration }\end{array}$ & Location & References \\
\hline 1 & 104.8 & 19.6 & Until 1988 & Nghe An & {$[6]$} \\
\hline 2 & 104.2 & 19.4 & $1995-2002$ & Nghe An & [6] \\
\hline 3 & 104.4 & 19.3 & 1995-2002 & Nghe An & {$[37,38]$} \\
\hline 4 & 104.4 & 19.3 & 1989-1994 & Nghe An & {$[37,38]$} \\
\hline 5 & 105.0 & 19.2 & 1989-1994 & Nghe An & [6] \\
\hline 6 & 104.6 & 19.1 & 1989-1994 & Nghe An & {$[37,38]$} \\
\hline 7 & 104.5 & 19.0 & 1989-1994 & Nghe An & {$[37,38]$} \\
\hline 8 & 104.9 & 19.0 & 1989-1994 & Nghe An & {$[37,38]$} \\
\hline 9 & 104.7 & 19.0 & $1995-2002$ & Nghe An & [6] \\
\hline 10 & 104.8 & 19.0 & Until 1988 & Nghe An & [6] \\
\hline 11 & 104.9 & 18.8 & 1989-1994 & Nghe An & {$[37,38]$} \\
\hline 12 & 105.5 & 18.5 & Until 1988 & Ha Tinh & {$[6,39]$} \\
\hline 13 & 105.3 & 18.5 & Until 1988 & Ha Tinh & {$[6,39]$} \\
\hline 14 & 105.8 & 18.5 & Until 1988 & Ha Tinh & {$[6]$} \\
\hline 15 & 105.7 & 18.4 & $1995-2002$ & Ha Tinh & [6] \\
\hline 16 & 105.8 & 18.3 & Until 1988 & Ha Tinh & [6] \\
\hline 17 & 105.6 & 18.3 & Until 1988 & Ha Tinh & {$[40,41]$} \\
\hline 18 & 105.4 & 18.3 & 1989-1994 & Ha Tinh & {$[40,41]$} \\
\hline 19 & 105.7 & 18.2 & Until 1988 & Ha Tinh & [6] \\
\hline 20 & 105.6 & 18.2 & Until 1988 & Ha Tinh & [6] \\
\hline 21 & 105.7 & 18.2 & Until 1988 & Ha Tinh & [6] \\
\hline 22 & 105.9 & 18.2 & 1989-1994 & Ha Tinh & {$[37,42]$} \\
\hline 23 & 106.3 & 18.1 & 1989-1994 & Ha Tinh & [6] \\
\hline 24 & 106.2 & 18.1 & Until 1988 & Ha Tinh & [6] \\
\hline 25 & 105.6 & 18.1 & 1989-1994 & Ha Tinh & [6] \\
\hline 26 & 106.1 & 18.0 & Until 1988 & Ha Tinh & [6] \\
\hline 27 & 106.5 & 18.0 & Until 1988 & Quang Binh & [6] \\
\hline 28 & 106.0 & 17.8 & 1989-1994 & Quang Binh & [43] \\
\hline 29 & 105.9 & 17.7 & $1995-2002$ & Quang Binh & [43] \\
\hline 30 & 105.9 & 17.7 & $1995-2002$ & Quang Binh & [43] \\
\hline 31 & 106.0 & 17.7 & $1995-2002$ & Quang Binh & [43] \\
\hline 32 & 106.1 & 17.6 & $1995-2002$ & Quang Binh & [43] \\
\hline 33 & 106.3 & 17.6 & $1995-2002$ & Quang Binh & [44] \\
\hline 34 & 106.4 & 17.6 & 1989-1994 & Quang Binh & [41] \\
\hline 35 & 106.2 & 17.5 & $1995-2002$ & Quang Binh & [41] \\
\hline 36 & 106.3 & 17.5 & $1995-2002$ & Quang Binh & [41] \\
\hline 37 & 106.2 & 17.5 & $1995-2002$ & Quang Binh & [41] \\
\hline 38 & 106.2 & 17.4 & $1995-2002$ & Quang Binh & [41] \\
\hline 39 & 106.8 & 17.2 & 1989-1994 & Quang Binh & {$[6]$} \\
\hline 40 & 106.9 & 17.0 & $1995-2002$ & Quang Tri & [6] \\
\hline 41 & 107.5 & 16.1 & 2016 & Hue & Personal data \\
\hline 42 & 107.0 & 16.5 & $1995-2002$ & Quang Tri & {$[45]$} \\
\hline 43 & 107.2 & 16.5 & $1995-2002$ & Hue & [45] \\
\hline 44 & 107.2 & 16.4 & $1995-2002$ & Hue & [45] \\
\hline 45 & 107.8 & 16.2 & Until 1988 & Hue & [46] \\
\hline 46 & 108.1 & 16.2 & $1995-2002$ & Hue & [47] \\
\hline 47 & 107.9 & 16.2 & $1995-2002$ & Hue & [46] \\
\hline 48 & 108.3 & 16.2 & Until 1988 & Da Nang & {$[48,49]$} \\
\hline
\end{tabular}




\begin{tabular}{llllll}
\hline 49 & 108.1 & 16.1 & $1995-2002$ & Da Nang & {$[50]$} \\
50 & 107.8 & 16.1 & $1995-2002$ & Da Nang & {$[51]$} \\
51 & 108.3 & 16.1 & $1995-2002$ & Da Nang & {$[48,49]$} \\
52 & 108.2 & 16.1 & $1989-1994$ & Da Nang & {$[48,49]$} \\
53 & 108.2 & 16.1 & Until 1988 & Da Nang & {$[48,49]$} \\
54 & 107.7 & 15.8 & $1995-2002$ & Quang Nam & {$[51]$} \\
55 & 107.8 & 15.6 & $1995-2002$ & Quang Nam & {$[51,52]$} \\
56 & 107.6 & 15.6 & $1995-2002$ & Quang Nam & {$[51,52]$} \\
57 & 107.4 & 15.5 & $1995-2002$ & Quang Nam & {$[51,52]$} \\
58 & 107.6 & 14.7 & $1995-2002$ & Kon Tum & {$[6,53]$} \\
59 & 108.6 & 14.5 & $1995-2002$ & Gia Lai & {$[6]$} \\
60 & 107.8 & 14.4 & $1995-2002$ & Kon Tum & {$[6,53]$} \\
61 & 108.6 & 14.4 & $1995-2002$ & Gia Lai & {$[6]$} \\
62 & 108.4 & 14.3 & $1995-2002$ & Gia Lai & {$[6]$} \\
\hline
\end{tabular}

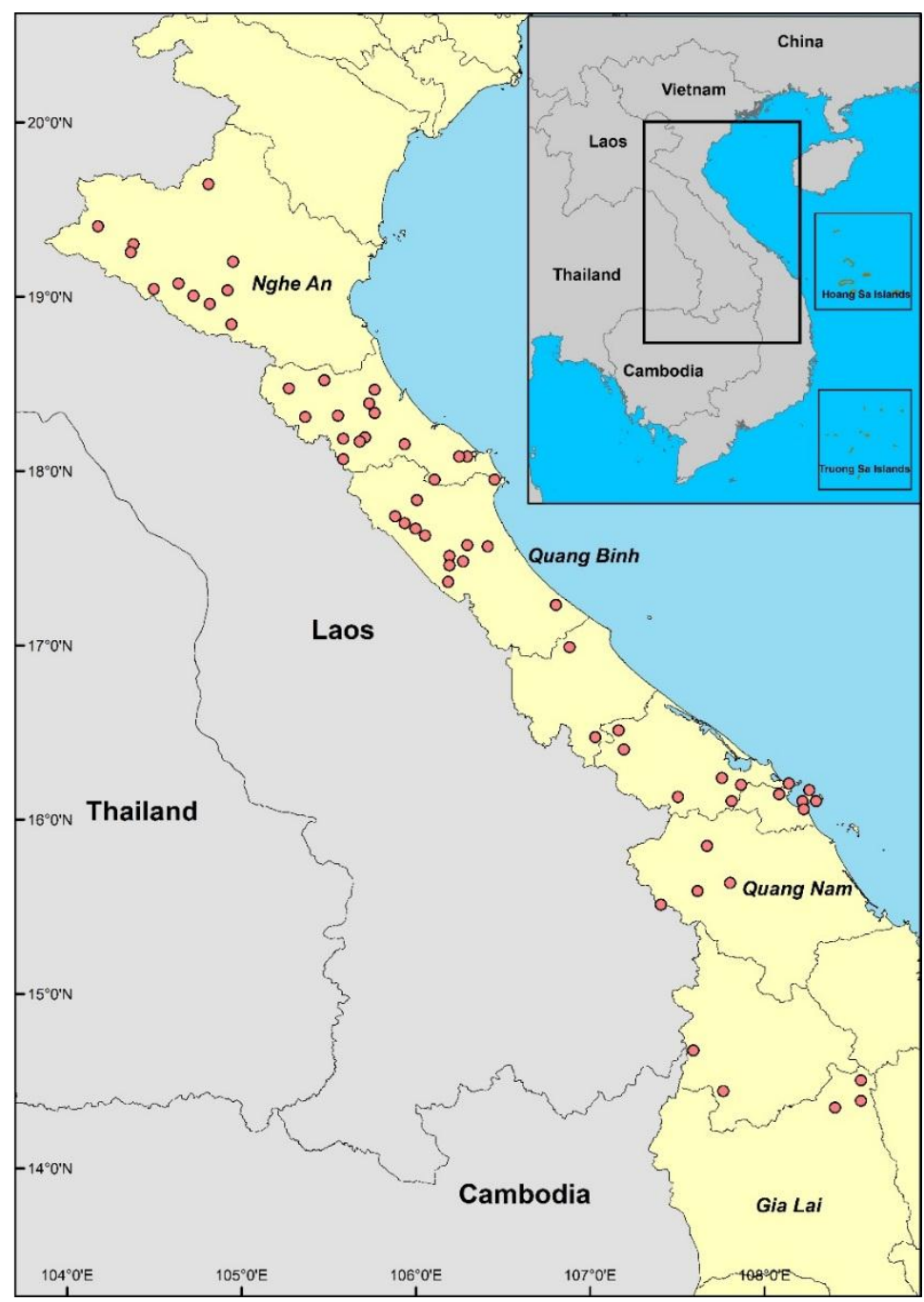

Fig. 1. All 62 collected records of the Red-shanked Douc in Vietnam. 
For the SDM, Maxent models showed reasonable prediction power for the distribution of the Red-shanked Douc, with the average AUC values $>0.8$. The best model had an AUC value of 0.81. All final SDMs were quite similar in terms of predicting the overall distribution of $P$. nemaeus and only differed slightly in exact locations and total suitable areas.

According to the model results, the northern limit of distribution range of the Red-shanked Douc appears to fall in the northern part of Nghe An Province, and the southern limit is in Kon Tum region. However, the regularization multiplier value of 1.5 for the best model means that the final model may be prone to underpredicting and over-fitting, which resulted in a fragmented distribution. Also, the equal training sensitivity and specificity threshold, which optimized the predicted area versus the omission error, further reduced the suitable area. The final prediction should therefore be carefully interpreted as "core zones", or regions that are highly likely suitable for the Red-shanked Douc, rather than potential distribution ranges (Fig. 2). Also, as occurrence records are often more prone to subjective flaws of survey methods at the extremes of distribution range, we suggest that suitable areas at northern and southern limits (i.e., North of Pu Mat National Park and South of Song Thanh Nature Reserve) should be considered with caution.

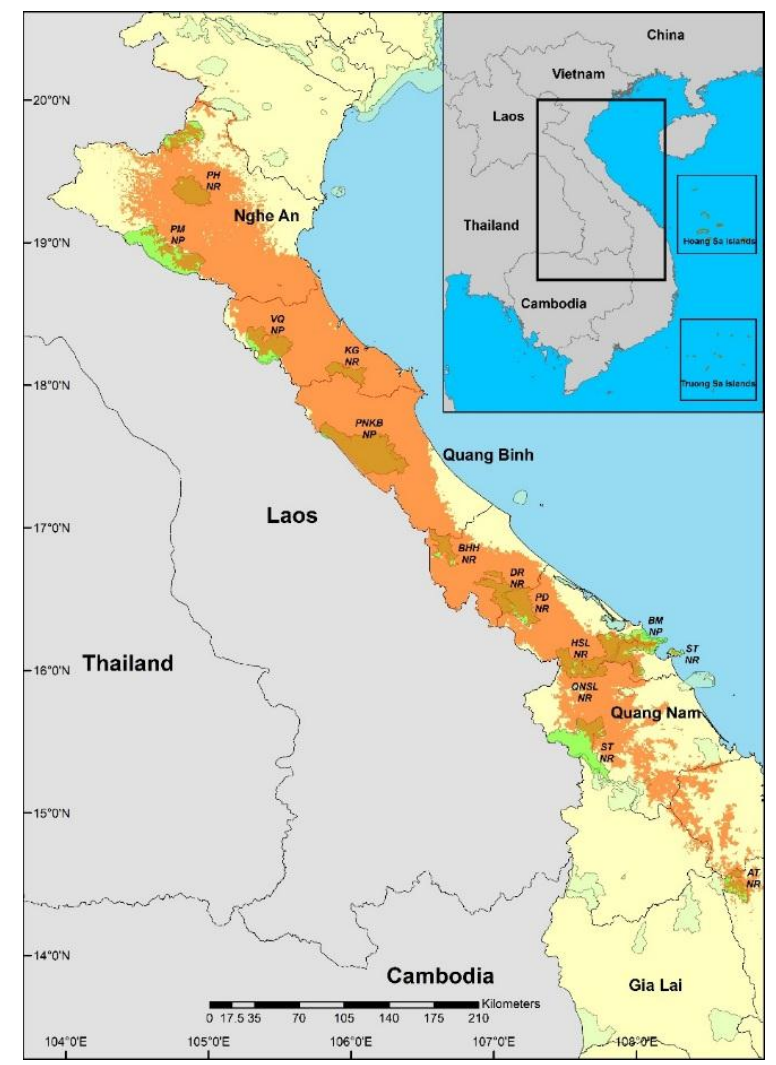

Fig. 2. Species distribution model for the Red-shanked Douc using Maxent. The green areas are protected areas that are in distribution range of the Red-shanked Douc, according to model results. Abbreviation in map from

North to South: PH NR - Pu Huong Nature Reserve, PM NP - Pu Mat National Park, VQ NP - Vu Quang National Park, KG NR - Ke Go Nature Reserve, PNKB NP - Phong Nha Ke Bang National Park, BHH NR Bac Huong Hoa Nature Reserve, DR NR - Dakrong Nature Reserve, PD NR - Phong Dien Nature Reserve, BM NP - Bach Ma National Park, HSL NR - Hue Saola Nature Reserve, ST NR - Son Tra Nature Reserve, QNSL NR-Quang Nam Saola Nature Reserve, ST NR-Song Thanh Nature Reserve, AT NR - An Toan Nature Reserve. 
Based on this result, we suggest the following protected areas, which lie within the largely continuous and climatically suitable habitats for the doucs, to be prioritized for more extensive and thorough conservation measures. They include:

Vu Quang National Park and Ke Go Nature Reserve (Ha Tinh): Given that both of them are highly prioritized areas that have lots of conservation works invested in in recent years [54-57], they may support a significant population of the Red-shanked Douc.

Phong Nha - Ke Bang National Park (Quang Binh): Not only is it one of two sites that supported the highest known population of the doucs $[41,44,58]$ in Vietnam, but also it has clear advantages in douc conservation as one of Vietnam's largest protected areas. The National Park proximity to Laos' Hin Nam No National Protected Area also expands the habitat into the neighboring region, where a healthy douc population occurs [8].

Bac Huong Hoa Nature Reserve (Quang Tri): Given the continuous records of the Redshanked Douc in recent years, as well as its status as a site containing last remaining populations of large mammals such as the Gaur or Black Bear [59], it is an important area for douc conservation.

Dakrong and Phong Dien Nature Reserves (Quang Tri - Thua Thien Hue): Given continuous records of the douc [60], and the fact that habitats in those two protected areas are quite similar due to their proximity [45], this region may play a significant role in species conservation.

Bach Ma National Park and Hue and Quang Nam Saola Nature Reserves (Thua Thien Hue Quang Nam): Even though not particularly wellstudied, but with recent records of the douc [61], and the fact that they together form a large continuous protected block in Truong Son region, they should be ranked in top priority sites for the douc conservation
Bac - Nam Hai Van special forest areas, Ba $\mathrm{Na}-$ Nui Chua and Son Tra Nature Reserves (Thua Thien Hue - Quang Nam): Officially the most famous and recognized habitat of the $P$. nemaeus, the area supports a reasonably healthy population of the species $[5,10]$.

Also based on model results, we suggest the following areas, despite falling outside main protected areas system, may still support the Red-shanked Douc population and should be considered for future survey efforts and conservation initiatives. They include:

Huong Son (Ha Tinh): It lies between two important areas for northern range of the douc, $\mathrm{Pu}$ Mat and Vu Quang national parks. It has been noted as a potential area with rich biodiversity value, and have been under threat from illegal hunting [62]

Quang Trach and Bo Trach (Quang Binh): They are close to arguably one of the most important sites for primate conservation in Vietnam, Phong Nha - Ke Bang National Park, and have been shown to have several douc populations [63,64]. Although it is still unclear if the doucs there were just temporal emigration populations from Phong Nha - Ke Bang, the sites are still important for primate conservation.

Nam Dong (Thua Thien Hue): It is located in the middle of all three protected areas that were confirmed to have the presence of the Redshanked Douc, two Saola Nature Reserves and Bach Ma National Park [5, 6, 61]. In the future, it should be considered as an extension of the protected areas for better protection from local rangers.

According to the SDM results, the species readily inhabit in both side of Hai Van Pass, which plays a major role in dividing climate between North and South Vietnam. Therefore, it may be suggested that bio-climatically speaking, the Red-shanked Douc exhibits characteristics of a generalist species, and consequently, its population more prone to illegal hunting and habitat destruction than changing climate. 
The Red-shanked Douc is known to inhabit all three countries of Indochina, but it is highly likely to be present in a restricted part of northern Cambodia [3], and Vietnam and Laos may house the largest and most significant populations in terms of conservation of the doucs [7]. One study, which modelled the distribution of $P$. nemaeus around Nakai - Nam Theun protected area using Maxent, found that $P$. nemaeus inhabits regions close to Vietnam (the Truong Son Range) [12]. Another research studied the niche conservatism, i.e., species tendency to retain basal ecological characteristics, also using Maxent, in all three Pygathrix species in their whole native range [65]. Although they were able to collect and compile a large number of occurrence records, many of those, in our opinion, were questionable, as they were way outside the known range of the doucs, and some were even located in areas close to Vietnam China border. These records might be erroneously taken from museum collections or trade information.

\section{Conclusion}

In this study, 62 occurrence records of the Red-shanked Douc in Vietnam were collected from existing sources. After screening the data, 52 high quality localities with low probabilities of autocorrelation were included in the final dataset. Maxent, a commonly employed method for species distribution modeling, was used to build and predict current distribution of the doucs. After tuning and evaluating, Maxent models showed reasonable prediction power with the average AUC values $>0.8$, and the best model had an AUC value of 0.81. All final SDMs were similar in terms of overall distribution pattern of Pygrathrix nemaeus. However, as the final model was built using a more conservative approach with low regularization multiplier value and threshold of equal training sensitivity and specificity, the distribution map presented here should be interpreted as core zones for already existing population, not potential zones for any population discovery survey. The results showed that $P$. nemaeus inhabits areas from Nghe An to Kon Tum Province, with areas from Ha Tinh, Quang Binh, Quang Tri, Thua Thien - Hue, Da Nang - Quang Nam exhibiting the highest potential for its distribution. With all model parameters already listed here, other studies in future may incorporate more records to develop better models, or other environmental variables to assess the influence of different factors on the species.

\section{Acknowledgements}

We thank the Department of Environmental Ecology, Faculty of Environmental Science, VNU Hanoi University of Science, and the Central Institute for Natural Resources and Environmental Studies for their support.

\section{References}

[1] K.N. Sterner, R.L. Raaum, Y.P. Zhang, C.B. Stewart, T.R. Disotell, Mitochondrial data support an odd-nosed colobine clade, Molecular Phylogenetics and Evolution 40 (2006) 1-7. https://doi.org/10.1016/j.ympev.2006.01.017.

[2] T.N.E. Gray, A.C. Hughes, W.F. Laurance, B. Long, A.J. Lynam, H. O'Kelly, W.J. Ripple, T. Seng, L. Scotson, N.M. Wilkinson, The wildlife snaring crisis: an insidious and pervasive threat to biodiversity in Southeast Asia, Biodiversity and Conservation 27 (2018) 1031-1037. https:// doi.org/10.1007/s10531-017-1450-5.

[3] B. Rawson, C. Roos, A new primate record for Cambodia: Pygathrix nemaeus, Cambodian Journal of Natural History 1 (2008) 7-11.

[4] R.J. Timmins, J.W. Duckworth, Status and conservation of Douc langurs (Pygathrix nemaeus) in Laos, International Journal of Primatology 20 (1999) 469-489. https://doi.org/ 10.1023/A:1020382421821.

[5] L. Ulibarri, The socioecology of Red-shanked doucs (Pygathrix nemaeus) in Son Tra Nature Reserve, Vietnam, Philosophy of Doctor Dissertation, Department of Anthropology, University of Colorado, Boulder, Colorado, 2013.

[6] T. Nadler, F. Momberg, N.X. Dang, N. Lormee, Vietnam Primate Conservation Status Review 2002. Part 2: Leaf Monkeys, Fauna \& Flora 
International-Asia Pacific Programme, Hanoi, 2003.

[7] V.N. Thanh, L. Lippold, R.J. Timmins, N.M. Ha, Pygathrix nemaeus - The IUCN Red List of Threatened Species 2008: e.T39826A10272920, International Union for Conservation of Nature, Switzerland, 2015.

[8] P. Phiapalath, Distribution, Behavior And Threat Of Red-Shanked Douc Langur Pygathrix Nemaeus In Hin Namno National Protected Area, Khammouane Province, Lao PDR, Philosophy of Doctor Dissertation, Suranaree University of Technology, Thailand, 2009.

[9] C.N.Z. Coudrat, J.W. Duckworth, R.J. Timmins, Distribution and Conservation Status of the RedShanked Douc (Pygathrix nemaeus) in Lao PDR: An Update, American Journal of Primatology 74 (2012) 874-889. https://doi.org/10.1002/ajp.22027.

[10] H.H. Covert, H.M. Duc, L.K. Quyet, A. Ang, A. Harrison-Levine, T.V. Bang, Primates of Vietnam: Conservation in a Rapidly Developing Country, Anthropology Now 9 (2018) 27-44. https://doi.org/10.1080/19428200.2017.1337353.

[11] M.E. Blair, E.J. Sterling, M.M. Hurley, Taxonomy and conservation of Vietnam's primates: A review, American Journal of Primatology 73 (2011) 1093-1106. https:// doi.org/10.1002/ajp.20986.

[12] C.N.Z. Coudrat, C. Nanthavong, K.A.I. Nekaris, Conservation of the red-shanked douc Pygathrix nemaeus in Lao People's Democratic Republic: Density estimates based on distance sampling and habitat suitability modelling, Oryx 48 (2014) 540-547. https://doi.org/10.1017/S00306053130 00124.

[13] J. Elith, C.H. Graham, R.P. Anderson, M. Dudík, S. Ferrier, A. Guisan, R. J. Hijmans, F. Huettmann, J. R. Leathwick, A. Lehmann, J. Li, L. G. Lohmann, B. A. Loiselle, G. Manion, C. Moritz, M. Nakamura, Y. Nakazawa, J. McC. M. Overton, A. Townsend Peterson, S. J. Phillips, K. Richardson, R. Scachetti-Pereira, R. E. Schapire, J. Soberón, S. Williams, M. S. Wisz, N. E. Zimmermann, Novel methods improve prediction of species' distributions from occurrence data, Ecography 29 (2006) 129-151. https://doi.org/10.1111/j.2006.0906-7590.04596.x.

[14] R.G. Pearson, C.J. Raxworthy, M. Nakamura, A.T. Peterson, Predicting species distributions from small numbers of occurrence records: A test case using cryptic geckos in Madagascar, Journal of Biogeography 34 (2007) 102-117. https://doi. org/10.1111/j.1365-2699.2006.01594.x.
[15] N.J. Gotelli, J. Stanton-Geddes, Climate change, genetic markers and species distribution modelling, Journal of Biogeography 42 (2015) 1577-1585. https://doi.org/10.1111/jbi.12562.

[16] H. Samejima, E. Meijaard, J.W. Duckworth, S. Yasuma, A.J. Hearn, J. Ross, A. Mohamed, R. Alfred, H. Bernard, R. Boonratana, J.D. Pilgrim, J. Eaton, J.L. Belant, S. Kramer-Schadt, G. Semiadi, A. Wilting, Predicted distribution of the Sunda stink-badger Mydaus javanensis (Mammalia: Carnivora: Mephitidae) on Borneo, Raffles Bulletin of Zoology 2016 (2016) 61-70.

[17] J. Elith, M. Kearney, S. Phillips, The art of modelling range-shifting species, Methods in Ecology and Evolution 1 (2010) 330-342. https://doi.org/10.1111/j.2041-210X.2010.00036.x.

[18] B.A. Bradley, D.S. Wilcove, M. Oppenheimer, Climate change increases risk of plant invasion in the Eastern United States, Biological Invasions 12 (2010) 1855-1872. https://doi.org/10.1007/ s10530-009-9597-y.

[19] J.R. Milanovich, W.E. Peterman, N.P. Nibbelink, J.C. Maerz, Projected loss of a salamander diversity hotspot as a consequence of projected global climate change, PLoS ONE 5 (2010) 1-10. https://doi.org/10.1371/journal.pone.0012189.

[20] P. Kumar, Assessment of impact of climate change on Rhododendrons in Sikkim Himalayas using Maxent modelling: Limitations and challenges, Biodiversity and Conservation 21 (2012) 1251-1266. https://doi.org/10.1007/s10 531-012-0279-1.

[21] R. Khanum, A.S. Mumtaz, S. Kumar, Predicting impacts of climate change on medicinal asclepiads of Pakistan using Maxent modeling, Acta Oecologica 49 (2013) 23-31. https://doi. org/10.1016/j.actao.2013.02.007.

[22] P. Illoldi-Rangel, V. Sanchez-Cordero, A.T. Peterson, Predicting distributions of Mexican mammals, Journal of Mammalogy 85 (2004) 658-662.

[23] P. Chen, E.O. Wiley, K.M. Mcnyset, Ecological niche modeling as a predictive tool: Silver and bighead carps in North America, Biological Invasions 9 (2007) 43-51. https://doi.org/ 10.1007/s10530-006-9004-x.

[24] J.J. Wiens, C.H. Graham, Niche Conservatism: Integrating Evolution, Ecology, and Conservation Biology, Annual Review of Ecology, Evolution, and Systematics 36 (2005) 519-539. https://doi.org/10.1146/annurev.ecol sys.36.102803.095431. 
[25] J.J. Wiens, D.D. Ackerly, A.P. Allen, B.L. Anacker, L.B. Buckley, H. V Cornell, E.I. Damschen, T. Jonathan Davies, J.-A. Grytnes, S.P. Harrison, B.A. Hawkins, R.D. Holt, C.M. McCain, P.R. Stephens, Niche conservatism as an emerging principle in ecology and conservation biology, Ecology Letters 13 (2010) 1310-24. https://doi.org/10.1111/j.1461-0248. 2010.01515.x

[26] J. Miller, Species Distribution Modeling, Geography Compass 4 (2010) 490-509. https:// doi.org/10.1111/j.1749-8198.2010.00351.x.

[27] D.A. Fordham, H.R. Akçakaya, M.B. Araújo, D.A. Keith, B.W. Brook, Tools for integrating range change, extinction risk and climate change information into conservation management, Ecography 36 (2013) 956-964. https://doi. org/10.1111/j.1600-0587.2013.00147.x.

[28] M.E. Aiello-Lammens, R.A. Boria, A. Radosavljevic, B. Vilela, R.P. Anderson, spThin: an $\mathrm{R}$ package for spatial thinning of species occurrence records for use in ecological niche models, Ecography 38 (2015) 541-545. https://doi.org/10.1111/ecog.01132.

[29] R Core Team, R: A language and environment for statistical computing. https://cran.rproject.org/, 2018 (Accessed 15 February 2019).

[30] R.J. Hijmans, S.E. Cameron, J.L. Parra, P.G. Jones, A. Jarvis, Very high resolution interpolated climate surfaces for global land areas, International Journal of Climatology 25 (2005) 1965-1978. https://doi.org/10.1002/joc. 1276.

[31] D.L. Warren, S.N. Seifert, Ecological niche modeling in Maxent: the importance of model complexity and the performance of model selection criteria, Ecological Applications 21 (2011) 335-342. https://doi.org/10.1890/10-1171.1.

[32] S.J. Phillips, R.P. Anderson, R.E. Schapire, Maximum entropy modeling of species geographic distributions, Ecological Modelling 190 (2006) 231-259. https://doi.org/10.1016/j. ecolmodel.2005.03.026.

[33] S.J. Phillips, R.P. Anderson, M. Dudík, R.E. Schapire, M.E. Blair, Opening the black box: an open-source release of Maxent, Ecography 40 (2017) 887-893. https://doi.org/10.1111/ecog. 03049.

[34] J. Elith, S.J. Phillips, T. Hastie, M. Dudík, Y.E. Chee, C.J. Yates, A statistical explanation of MaxEnt for ecologists, Diversity and Distributions 17 (2011) 43-57. https://doi. org/10.1111/j.1472-4642.2010.00725.x.

[35] A.T. Peterson, J. Soberón, R.G. Pearson, R.P. Anderson, E. Martínez-Meyer, M. Nakamura, M.
Bastos Araujo, Ecological niches and geographic distributions, Princeton University Press, New Jersey, 2011.

[36] A. Radosavljevic, R.P. Anderson, Making better Maxent models of species distributions: complexity, overfitting and evaluation, Journal of Biogeography 41 (2014) 629-643. https://doi. org/10.1111/jbi.12227.

[37] R. Ratajszczak, R. Cox, H.D. Duc, A preliminary survey of primates in north Viet Nam, International Union for Conservation of Nature, Switzerland, 1990.

[38] J. Fooden, Zoogeography of Vietnamese primates, International Journal of Primatology 17 (1996) 845-899. https://doi.org/10.1007/BF027 35268.

[39] F. Rozenddal, Report on surveys in Hoang Lien Son, Lai Chau and Nghe Tinh Provinces, World Wildlife Fund-Indochina Programme, Hanoi, 1990.

[40] F. Lambert, J. Eames, N. Cu, Surveys for Endemic Pheasants in the Annamese Lowlands of Vietnam, June-July, 1994, International Union for Conservation of Nature, Switzerland, 1994.

[41] P. Nhat, D.Q. Huy, P.H. Nguyen, Report on Research Result on Distribution, Ecology and Monitoring Survey of the Red-shanked Douc Langurs (Pygathrix nemaeus nemaeus) in Phong Nha-Ke Bang Forest Area, World Wildlife FundIndochina Programme, Hanoi, 2000.

[42] L.T. Trai, N.H. Dung, N. Cu, L. Van Cham, J. Eames, G. Chicoine, An Investment Plan for Ke Go Nature Reserve, Ha Tinh Province, Vietnam, BirdLife International, Vietnam Programme, Hanoi, 1996.

[43] P. Nhat, D. Tuoc, T. Van La, Preliminary survey for the Hatinh Langur in North Central Vietnam, Asian Primates 6 (1996) 13-17.

[44] N.X. Dang, P. Nhat, P.T. Anh, D. Hendrichsen, Results of survey on mammal fauna in Phong Nha-Ke Bang area, Quang Binh, Vietnam, Fauna and Flora International-Indochina Programme, Hanoi, 1998.

[45] L.T. Trai, W. Richardson, A Feasibility Study for the Establishment of Phong Dien (Thua Thien Hue Province) and Dakrong (Quang Tri Province) Nature Reserves, Vietnam, BirdLife International, Vietnam Programme, Hanoi, 1999.

[46] H.V. Keo, V.N. Thinh, The Status of Douc Langur (Pygathrix nemaeus) and some Preliminary Results of Wildlife Conservation in Bach Ma National Park, in: Proceedings Paper in Workshop on a Conservation Action Plan for the Primates of Vietnam, Hanoi, 1998. 
[47] W. Osgood, Mammals of the Kelley-Roosevelts and Delacour Asiatic expeditions, Field Museum of Natural History, Zoological Series 18 (1932) 193-339.

[48] P. Nhat, Preliminary results on the diet of the Red-shanked douc langur (Pygathrix nemaeus), Asian Primates 4 (1994) 9-11.

[49] L. Lippold, Distribution and conservation status of Douc langurs in Vietnam, Asian Primates 4 (1995) 4-6.

[50] Anon., Feasibility Study for Ba Na Nui Chua, Quang Nam-Da Nang Province, Ministry of Forestry, Hanoi, 1994.

[51] H.T. Long, Douc langur Survey in Central and South Vietnam - May to July and October 2000, Frankfurt Zoological Society, Frankfurt, 2000.

[52] E. Wikramanayake, V.V. Dung, P.M. Giao, A Biological and Socio-economic Survey of West Quang Nam Province with Recommendations for a Nature Reserve, World Wildlife FundIndochina Programme, Hanoi, 1997.

[53] D. Tuoc, Features and Values of Fauna Component of the Chu Mom Ray Nature Reserve, Forest Inventory and Planning Institute, Hanoi, 1995.

[54] V.V. Dung, N.N. Chinh, D. Tuoc, P.M. Giao, J. MacKinnon, Discovery and conservation of the Vu Quang ox in Vietnam, Oryx 28 (1994) 16-21. https://doi.org/10.1017/S0030605300028246.

[55] N. Kemp, M. Dilger, N. Burgess, C.V. Dung, The saola Pseudoryx nghetinhensis in Vietnam - New information on distribution and habitat preferences, and conservation needs, Oryx 31 (1997) 37-44. https://doi.org/10.1046/j.13653008.1997.d01-86.x.

[56] D.P. Lunde, G.G. Musser, T. Ziegler, Description of a new species of Crocidura (Soricomorpha: Soricidae, Crocidurinae) from Ke Go Nature Reserve, Vietnam, Mammal Study 29 (2007) 27 36. https://doi.org/10.3106/mammalstudy.29.27.

[57] D. Willcox, T.Q. Phuong, N.V. Thai, N.V. Nhuan, J. Kempinski, S. Roberton, The conservation status of small carnivores in the Ke Go - Khe Net Lowlands, Central Vietnam, Small Carnivore Conservation 52\&53 (2015) 56-73.

[58] T. Haus, M. Vogt, B. Forster, N.T. Vu, T. Ziegler, Distribution and population densities of diurnal primates in the Karst Forests of Phong Nha - Ke Bang National Park, Quang Binh Province, Central Vietnam, International Journal of Primatology 30 (2009) 301-312. https://doi.org /10.1007/s10764-009-9343-4.

[59] S. Mahood, T.V. Hung, The Biodiversity of Bac Huong Hoa Nature Reserve, Quang Tri Province, Vietnam, BirdLife International-Vietnam Programme, Hanoi, 2008.

[60] N.D. Manh, N.X. Dang, N.X. Nghia, Conservation importance of mammal fauna in Dakrong Nature Reserve, Quang Tri Province, Journal of Biology 31 (2009) 42-50.

[61] Anon., Basic Information about Hue Saola Nature Reserve, Hue Department of Forest Protection, Hue, 2013.

[62] R.J. Timmins, T.V. Cuong, An assessment of the conservation importance of the Huong Son (Annamite) Forest, Ha Tinh Province,Vietnam, based on the results of a field survey for large mammals and birds, Center for Biodiversity and Conservation, at American Museum of Natural History, Hanoi, 2001.

[63] T.D. Le, T. Do, H.T. Dinh, T.D. Le, N.K. Dang, Census of Southern White-Cheeked Crested Gibbons in $\mathrm{U}$ Bo and Adjacent Bufferzone Forests, Phong Nha-Ke Bang National, Fauna and Flora International-Indochina Programme, Hanoi, 2009.

[64] Frankfurt Zoological Society, Biodiversity Survey of Macaque, Langur and Douc monkey in and around the Phong Nha - Ke Bang National Park, Quang Binh, Viet Nam, Frankfurt Zoological Society, Frankfurt, 2011.

[65] N.N. Bett, M.E. Blair, E.J. Sterling, Ecological Niche Conservatism in Doucs (Genus Pygathrix), International Journal of Primatology 33 (2012) 972 -988. https://doi.org/10.1007/s10764-012-9622-3. 